\title{
Correlation Between Suicide Attempts and a History of Childhood Abuse in Adults Referring to the Toxicity Emergency Units of Yazd City, Iran
}

\author{
Elham Bazdar ${ }^{1}$, Bonnie Bozorg ${ }^{2}$, Fatemeh Ayoobi ${ }^{3}$, Hamid Owliae ${ }^{1}$, Reza Bidaki ${ }^{4,5^{*}}$ \\ ${ }^{1}$ Ali e bene Abitaleb Medical School of Medicine, Islamic Azad University, Yazd, Iran \\ ${ }^{2}$ Shahid Beheshti University of Medical Sciences, Tehran, Iran \\ ${ }^{3}$ Non-Communicable Diseases Research Center, Rafsanjan University of Medical Sciences, Rafsanjan, Iran \\ ${ }^{4}$ Research Center of Addiction and Behavioral Sciences, Shahid Sadoughi University of Medical Sciences, Yazd, Iran \\ ${ }^{5}$ Diabetes Research Center, Shahid Sadoughi University of Medical Sciences, Yazd, Iran
}

*Corresponding Author: Reza Bidaki, M.D., Associate Professor, Research Center of Addiction and Behavioral Sciences, Shahid Sadoughi University of Medical Sciences, Yazd, Iran. Tel: +98-3536232003, Email: Reza_Bidaki@ yahoo.com

Received September 1, 2019; Accepted February 5, 2020; Online Published March 13, 2020

\begin{abstract}
Background: Child abuse is defined as any act or omission which causes physical or psychological harassment and lasting effects on children. Injuries resulting from child abuse are widespread, and this trauma can lead to psychological problems in adulthood. Objective: The aim of this study was to investigate the correlation between a history of child abuse and suicide attempts.

Methods: In this case-control and retrospective study, patients admitted in 2016 to the toxicity emergency center in Yazd city, Iran, with symptoms of attempted suicide and patients of other conditions were recruited. Participants in the control and case groups were matched for age, gender, marital status, and place of residence. Each patient was given a questionnaire to collect information on demographics, history of suicide attempt or suicide in other members of the family, and history of child abuse (self-report scale) which investigated five aspects of childhood abuse (sexual, physical, neglect, lack of nutrition, and emotional neglect).

Results: The chi-square test and $t$ test were used in the analysis. Mean severity rates of physical, sexual, neglect, nutrition, and emotional child abuse were $8.49,6.42,10.4,6.43$, and 9.62, respectively, for the case group and 7.89, 5.52, 7.88, 5.92, and 8.52, respectively, for the control group.

Conclusion: Statistical analysis revealed that except for nutritional abuse cases, the incidence rates of all other aspects of child abuse were significantly higher among cases than in the control group. The results of this study showed that a history of child abuse, especially sexual and emotional types, are correlated with the incidence of attempted suicide.

Keywords: Child abuse, Sexual, Suicide, Depression
\end{abstract}

\section{Background}

Child abuse is defined as any act or omission which causes physical or psychological harassment and has lasting effects on children. ${ }^{1}$ There are 5 aspects of child abuse, physical, emotional, and sexual abuse, neglect, and exploitation of children. ${ }^{1}$ Injuries and consequences of child abuse are widespread, and severe behavioral disorders resulting from such continuing harassment can be major depression, posttraumatic stress disorder, and also suicide attempts. ${ }^{2}$ Every year, one million people attempt or die from suicide. ${ }^{3}$ There are 10-20 times more suicide attempts than completed suicide. ${ }^{3,4}$ Iran is ranked 58th globally for suicide ${ }^{4}$; approximately 9 out of every 100000 people attempt suicide. ${ }^{4-6}$

Risk factors for suicide include old age, marital status, employment, interpersonal relationships, family history (chaotic, conflict), and chronic physical and/or mental disorders. ${ }^{3}$

In 2014, Miller et al studied adolescents in the United States and concluded that depression was a mediator of the relationship between childhood abuse and suicidal thoughts. ${ }^{7}$ In 2016, Daray et al found a significant and positive correlation between child sexual abuse and suicide attempts in young women. ${ }^{8}$ In 2016, Martin et al studied the relationship between child abuse and suicide attempts in adulthood in Canada. Their results indicated that child abuse increases the risk of future suicide attempt to 1.77 times more, regardless of other factors. ${ }^{9}$ Also in 2016, Fuller-Thomson et al investigated the correlation between different types of child abuse and attempted suicide in adulthood in Canada. It was found that the risk of suicide in child victims of emotional abuse, sexual abuse, and parental violence was $3.29,4.42$, and 2.52 , respectively. ${ }^{10}$ An often ignored factor in the emergence of

Copyright (C 2020 The Author(s). This is an open-access article distributed under the terms of the Creative Commons Attribution License (http:// creativecommons.org/licenses/by/4.0), which permits unrestricted use, distribution, and reproduction in any medium, provided the original work is properly cited. 
psychological problems in adolescence and adulthood is the history of childhood abuse. Less attention has been paid to studies related to suicide. There are also many families and patients who do not express having thoughts of suicide in psychiatric interviews and consultations. In many countries, Iran in particular, religious beliefs pronounce those who commit suicide as condemned; thus, no studies have investigated the effect of child abuse on this phenomenon in such countries. ${ }^{11}$

\section{Objective}

The current study investigated the correlation between a history of childhood abuse and attempted suicide in Iran.

\section{Methods}

This research was a descriptive, retrospective, case-control study. Patients presenting to toxicity units in all hospitals of Yazd city, Iran, from March 2016 to July 2016 were selected for the sample. A non-random sampling method was used, and participants were chosen from among patients who came to the hospital toxicity unit and met the inclusion criteria for this study. Patients who had attempted suicide were placed in the case group $(n=100)$; others referring for other causes were placed in the control group $(n=100)$. Consent to participate was obtained from all participants, and participants were assured that their information would be kept confidential.

Inclusion criteria for the case group comprised:

1. Poisoning with the intent of committing suicide;

2. Suicide attempt confirmed by an emergency medicine specialist;

3. Age between 14-80 years.

Exclusion criteria consisted of:

1. Attempted suicide by methods other than poisoning or poisoning with non-suicidal intention;

2. No willingness to participate in the study.

Control group participants were matched to case group participants by age, gender, marital status, and place of residency. The demographic questionnaire included questions on age, gender, socioeconomic status, marital status, place of residence, and family history of suicide. The child-abuse questionnaire (self-report scale) examined the following 4 aspects of child abuse: (1) physical abuse: intentional use of physical force against the child that results in - or has a high likelihood of resulting in - harm for the child's health, survival, development, or dignity, including hitting, beating, kicking, shaking, biting, strangling, scalding, burning, poisoning, and suffocating; (2) sexual abuse: child abuse in which an adult or older adolescent abuses a child for sexual stimulation; (3) emotional (or psychological) abuse: the production of psychological and social defects in the growth of a child as a result of behavior, such as loud yelling, coarse and rude attitude, inattention, harsh criticism, and denigration of the child's personality; and (4) neglect: the failure of a parent or other person responsible for the child to provide the necessary food, clothing, shelter, medical care, or supervision to the degree that the child's health, safety, or well-being may be threatened with harm.12 This questionnaire had 25 questions that evaluated the different aspects of child abuse using a Likert- type response range from very low to very high. The Persian version of this test for which validity and reliability have been previously demonstrated was used; Cronbach's $\alpha$ for the child abuse questionnaire were 0.69 for physical abuse, 0.72 for sexual abuse, 0.7 for neglect, and 0.82 for nourishment; for total child abuse, it was 0.8 .

The data from the questionnaires was entered into SPSS 20 software and analyzed by chi-square, $t$ test, and Fisher exact tests; the level of significance was set at 0.05 .

\section{Results}

The average age (mean \pm SD) of participants in the case group was $28.82 \pm 12.68$; maximum age was 80 and minimum age was 14 years. The average age for the control group was $30.71 \pm 9.73$; maximum and minimum ages were 58 and 14 years, respectively.

There were 42 males (42\%) and 58 females (58\%) in the case group and 41 males (41\%) and 59 females (59\%) in the control group. The results showed that there was no significant difference between these two groups in gender $(P=0.866)$. The results showed that among the participants in the case group, 48 were single (48\%) and 52 were married (51\%). In the control group, 45 (45\%) patients were single and $55(55 \%)$ were married. The chi-square test showed no significant difference in marital status between the two groups $(P=0.669)$. The location survey among participants showed that $93(93.9 \%)$ patients in the case group lived in a city and 7 (6.1\%) were from rural areas. In the control group, 96 patients (96\%) were from a city, 2 (2\%) were from a village, and $2(2 \%)$ were from the countryside. There was no significant difference between the two groups in place of residence $(P=0.132)$. The data further showed that 48 $(48 \%)$ patients in the case group had a poor economic status, $42(42 \%)$ had a moderate economic status, and 10 (10\%) patients had a good economic status. In the control group, 25 (25\%), 65 (65\%), and 10 (10\%) participants had a poor, average, and good economic situation, respectively. The difference seen between the two groups in terms of economic parameters was significant $(P<0.001$; Table 1$)$.

The data for the case group showed that 11 patients had a history of self-attempt suicide and 9 patients had a history of suicidal attempts in their family. There was no history of suicidal attempts in the patients or their families in the control group. A significant difference was seen between the case and control groups in this parameter $(P=0.001$ and $P=0.003$, respectively) (Table 1 ).

The data showed that the rates of severity of physical, sexual, neglect, malnourishment, and emotional child abuse were $8.49,6.42,10.43,6.43$, and 9.62, respectively, in the case group and $7.89,5.52,7.88,5.92$, and 8.52 , respectively, in the control group. Analytical statistics of this study revealed significant differences between the two groups in all aspects of child abuse except nourishment (Table 2). 
Table 1. Demographic Characteristics in Patients of Case and Control Groups

\begin{tabular}{|c|c|c|c|}
\hline & Case $(n=100)$ & Control $(n=100)$ & $P$ value \\
\hline \multicolumn{4}{|l|}{ Age (y) } \\
\hline Range & $14-80$ & $14-58$ & 0.866 \\
\hline Mean \pm SD & $28.82 \pm 12.68$ & $30.71 \pm 9.73$ & 0.866 \\
\hline Male, No. (\%) & $42(42.0)$ & $41(41.0)$ & \\
\hline \multicolumn{4}{|l|}{ Marital status, No. (\%) } \\
\hline Single & $48(48.0)$ & $45(45.0)$ & 0.669 \\
\hline Married & $52(52.0)$ & $55(55.0)$ & 0.669 \\
\hline \multicolumn{4}{|l|}{ Locations live, No. (\%) } \\
\hline City & $93(93.0)$ & $96(96.0)$ & 0.132 \\
\hline Rural area & $7(7.0)$ & $4(4.0)$ & 0.132 \\
\hline \multicolumn{4}{|l|}{ Economic situation, No. (\%) } \\
\hline Poor & $48(48.0)$ & $25(25.0)$ & $<0.001$ \\
\hline Moderate & $42(42.0)$ & $65(65.0)$ & $<0.001$ \\
\hline Good & $10(10.0)$ & $10(10.0)$ & \\
\hline \multicolumn{4}{|l|}{ Suicide history, No. (\%) } \\
\hline Self-attempt & $11(11.0)$ & $0(0.0)$ & 0.001 \\
\hline Attempt of family member & $9(9.0)$ & $0(0.0)$ & 0.003 \\
\hline
\end{tabular}

Table 2. Frequency of Child Abuse in Patients of Case and Control Groups

\begin{tabular}{lccc}
\hline \multirow{2}{*}{ Child abuse aspects } & \multicolumn{2}{c}{ Groups } & \multirow{2}{*}{$\boldsymbol{P}$ value } \\
\cline { 2 - 3 } & Case $(\mathbf{n}=\mathbf{1 0 0})$ & Control $(\mathbf{n = 1 0 0})$ & \\
\hline Physical, Mean \pm SD & $8.49 \pm 2.01$ & $7.89 \pm 1.94$ & 0.033 \\
(Range) & $(5-15)$ & $(5-13)$ & \\
Sexual, Mean \pm SD & $6.42 \pm 1.4$ & $5.52 \pm 1.39$ & $<0.001$ \\
(Range) & $(5-11)$ & $(5-13)$ & \\
Neglect, Mean \pm SD & $10.43 \pm 2.69$ & $7.88 \pm 2.4$ & $<0.001$ \\
(Range) & $(5-18)$ & $(5-16)$ & \\
Malnourishment, Mean \pm SD & $6.43 \pm 1.9$ & $5.92 \pm 2.14$ & 0.077 \\
(Range) & $(5-13)$ & $(5-17)$ & \\
Emotional, Mean \pm SD & $9.62 \pm 2.91$ & $8.52 \pm 2.72$ & 0.006 \\
(Range) & $(5-20)$ & $(5-17)$ & \\
Overall - Mean \pm SD & $41.39 \pm 7.24$ & $35.73 \pm 8.17$ & $<0.001$ \\
(Range) & $(27-64)$ & $(27-70)$ & \\
\hline
\end{tabular}

\section{Discussion}

The aim of this study was to investigate the relationship between a history of child abuse and suicide. The results implied that a history of child abuse, especially sexual and emotional types, are correlated with incidence of future suicide attempts.

The data showed that 11 patients and 9 members of patients' families in the case group had a history of attempted suicide. There were no previous suicide attempts in the control group. There was a significant difference between these two groups in terms of suicide history in patients and their families ( $P=0.001$ and $P=0.003$, respectively).

A comprehensive study of the intensity of physical, sexual, neglect, malnourishment, and emotional child abuse revealed rates of $8.49,6.42,10.43,6.43$, and 9.62, respectively, in the case group and $7.89,5.52,7.88,5.92$, and 8.52 , respectively, in the control group.

The results of this study are consistent with those of Fanning, Marin, and Daray. ${ }^{8,9,13}$ The present results are congruent with those of Fanning et al, who studied child abuse and suicidal behavior in 2014 in the United States. In this study, people who had a history of child abuse had a higher number of suicide attempts than others. ${ }^{13}$

In 2016, Daray et al investigated the correlation between child sexual abuse and suicide attempts in the lives of young women in Argentina. Their results showed a significant and positive correlation between sexual abuse and suicide attempts in young women. ${ }^{8}$ This result is in agreement with the current result that showed that the correlation between sexual abuse and suicide is greater in women. Suicidal thoughts and attempts are more common in women who have been sexually abused, because these women have usually suffered sexual violence in addition to the abuse. Two thirds of women who have been sexually abused in childhood are likely to be sexual assaulted in their adulthood. These girls ran away from home after being abused and are, therefore, more vulnerable. Moreover, such women psychologically need to be harassed and to increase their feelings of worthlessness. ${ }^{14}$

In 2016 in Canada, Martin et al studied the relationship between child abuse and adulthood suicide attempts. Their results indicated that child abuse increased the risk of suicide attempt up to 1.77 more than other groups. ${ }^{9}$ This result is consistent with the findings of the present study that emotional abuse, sexual abuse, and neglect were higher in the case group than the other aspects of child abuse.

It seems depression is the intermediate parameter of child abuse and incidence of suicide. Miller and Sigfusdottir also achieved these results. ${ }^{7,15}$ Sigfusdottir et al conducted a study on 9805 students aged 16-19 in Iceland in 2004. Based on their results, they concluded that there was a correlation between depression, anger, aggression, sexual abuse in families and suicide attempts. ${ }^{15}$ This result was consistent with the present study. The above-mentioned studies showed that some victims of child sexual abuse turn their anger and aggression inward toward themselves and caused damage to themselves. This demonstrates the relationship between childhood sexual abuse, adult sexual dysfunction and impotency, depression, suicidal thoughts and eventual suicide attempts. ${ }^{16}$

Miller et al studied American adolescents and concluded that depression is partially a mediating factor between abuse in childhood and suicidal thoughts. ${ }^{7}$

\section{Conclusion}

The results of the current study revealed the relationship between a history of child abuse and future incident of suicide attempt, which is commonly seen in victims of emotional or sexual abuse. Abuse in childhood, especial sexual, is associated with attempts at suicide.

\section{Authors' Contributions}

EB helped in conducting the study; $\mathrm{BB}, \mathrm{RB}$, and FA wrote and revised the manuscript; $\mathrm{RB}$ and $\mathrm{HO}$ developed the study design and concept. 


\section{Conflict of Interest Disclosures}

The authors declare that they have no conflicts of interest to disclose.

\section{Ethical Approval}

This study was approved by the Institutional Review Board and local Ethics Committee of Yazd University of Medical Sciences (No. 9/459).

\section{Acknowledgments}

The authors would like to thank the personnel of Shahid Beheshti Hospital in Taft city, Iran, who helped us in this research. The authors would also like to thank the members of the research committee of the Ali-Ebn-Abitaleb faculty of Islamic Azad University in Yazd city, Iran. This article is extracted from a medical student's thesis for a doctoral degree in medicine at Islamic Azad University of Yazd, and it has been registered.

\section{References}

1. Carter S, Godard K. Investigating Child Abuse: Examining the Resources of Multidisciplinary Teams. 2019 Undergraduate Research and Scholarship Conference. https://scholarworks. boisestate.edu/under_conf_2019/25.

2. Sakelliadis El, Spiliopoulou CA, Papadodima SA. Forensic investigation of child victim with sexual abuse. Indian Pediatr. 2009:46(2):144-151.

3. Palmer S. Suicide: Strategies and Interventions for Reduction and Prevention. Routledge; 2014.

4. Rezaeian M. Suicide/homicide ratios in countries of the Eastern Mediterranean Region. East Mediterr Health J. 2008;14(6):1459-1465.

5. Taghaddosinejad F, Sheikhazadi A, Behnoush B, Reshadati J, Sabery SH. A survey of suicide by burning in Tehran, Iran. Acta Med Iran. 2010;48(4):266-272.

6. Sheikholeslami H, Kani C, Ziaee A. Attempted suicide among Iranian population. Suicide Life Threat Behav. 2008;38(4):456466. doi:10.1521/suli.2008.38.4.456.

7. Miller AB, Adams LM, Esposito-Smythers C, Thompson R, Proctor LJ. Parents and friendships: a longitudinal examination of interpersonal mediators of the relationship between child maltreatment and suicidal ideation. Psychiatry Res. 2014;220(3):998-1006. doi:10.1016/j.psychres.2014.10.009.

8. Daray FM, Rojas SM, Bridges AJ, et al. The independent effects of child sexual abuse and impulsivity on lifetime suicide attempts among female patients. Child Abuse Negl.

\section{Research Highlights}

\section{What Is Already Known?}

The history of childhood abuse. Less attention has been paid to studies related to suicide. There are also many families and patients who do not express having thoughts of suicide in psychiatric interviews and consultations.

\section{What This Study Adds?}

This study increases our knowledge about the relationship and importance of suicide and child abuse. After this study, we know awareness and education are the key points for suicide management and assessment.

2016;58:91-98. doi:10.1016/j.chiabu.2016.06.011.

9. Martin MS, Dykxhoorn J, Afifi TO, Colman I. Child abuse and the prevalence of suicide attempts among those reporting suicide ideation. Soc Psychiatry Psychiatr Epidemiol. 2016;51(11):1477-1484. doi:10.1007/s00127-016-1250-3.

10. Fuller-Thomson E, Baird SL, Dhrodia R, Brennenstuhl S. The association between adverse childhood experiences (ACEs) and suicide attempts in a population-based study. Child Care Health Dev. 2016;42(5):725-734. doi:10.1111/cch.12351.

11. Rezaeian M, Vazirinejad R, Tabatabie SZ, Salem Z, Esmaili A. Suicide in Islamic faith. Journal of Rafsanjan University of Medical Sciences. 2007;6(4):15-30. [Persian].

12. Giovannoni JM, Becerra RM. Defining Child Abuse. New York: Free Press; 1979.

13. Fanning JR, Meyerhoff JJ, Lee R, Coccaro EF. History of childhood maltreatment in intermittent explosive disorder and suicidal behavior. J Psychiatr Res. 2014;56:10-17. doi:10.1016/j.jpsychires.2014.04.012.

14. Koola MM, Ahmed AO, Sebastian J, Duncan EJ. Childhood physical and sexual abuse predicts suicide risk in a large cohort of veterans. Prim Care Companion CNS Disord. 2018;20(4). doi:10.4088/PCC.18m02317.

15. Sigfusdottir ID, Asgeirsdottir BB, Gudjonsson GH, Sigurdsson JF. Suicidal ideations and attempts among adolescents subjected to childhood sexual abuse and family conflict/ violence: the mediating role of anger and depressed mood. J Adolesc. 2013;36(6):1227-1236. doi:10.1016/j. adolescence.2013.10.001.

16. Angelakis I, Gillespie EL, Panagioti M. Childhood maltreatment and adult suicidality: a comprehensive systematic review with meta-analysis. Psychol Med. 2019;49(7):1057-1078. doi:10.1017/s0033291718003823. 